\title{
Effects of reflective warning markers on wildlife
}

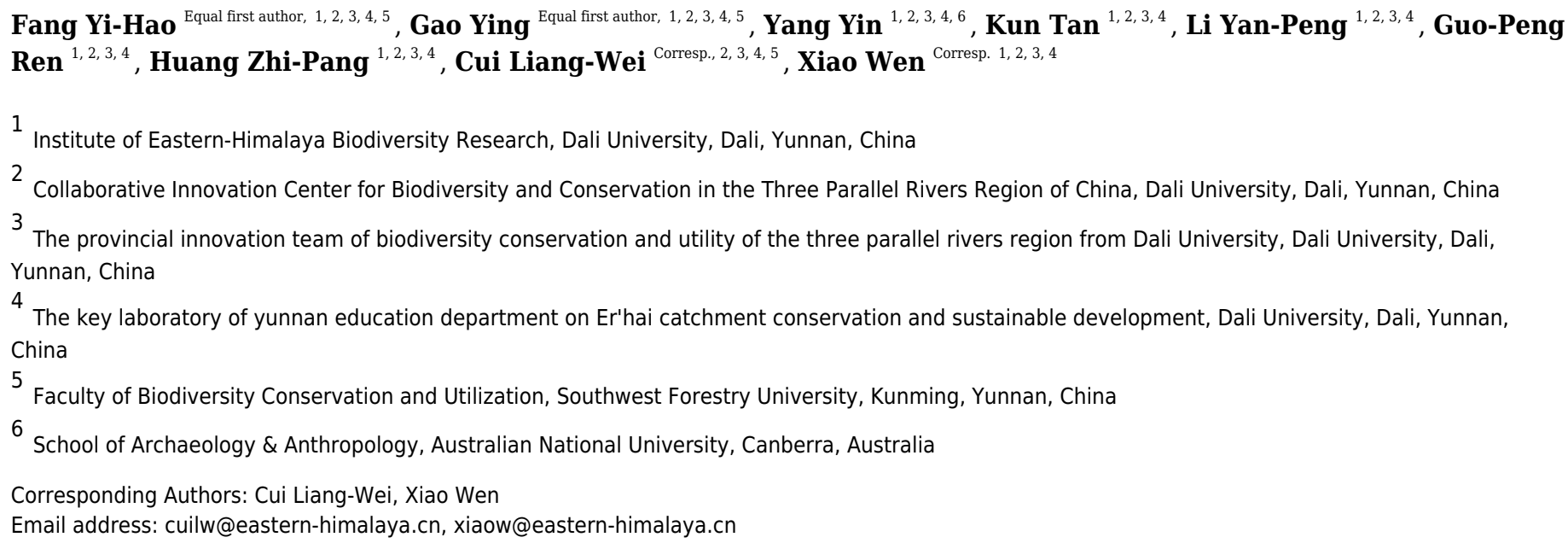

Light pollution has become one of the top issues in environmental pollution, especially concerning how secondary light pollution, such as from traffic reflective materials, influences animal distribution and behavior. In this study, 15 camera traps were set up at sites with or without reflective warning markers (RWM) in coniferous forests on Cangshan Mountain located in Dali Prefecture, China. The results showed that the number of independent photographs and species at sites without RWMs were significantly higher than those at sites with RWMs. Significant differences were found between daytime and nighttime composition of bird species and non-flying mammals between two sites. This study found that RWMs had negative effects on wildlife, with the avoidance response of birds to RWMs being more obvious than that of animals at daytime. It is recommended that the use of reflective materials be carefully considered, especially in protected areas. 
1 Effects of reflective warning markers on wildlife

2

3

4

5

6

7 China;

$8{ }^{2}$ Collaborative Innovation Center for the Biodiversity in the Three Parallel Rivers of China, Dali

9 University, Dali, Yunnan 671003, China;

10

Fang Yi-Hao 1, 2, 3,4,5\#, Gao Ying 1,2,3,4,5\#, Yang Yin 1,2,3,4,6, Kun Tan 1,2,3,4, Li Yan-Peng1,2,3,4, Ren Guo-Peng ${ }^{1,2,3,4}$, Huang Zhi-Pang ${ }^{1,2,3,4}$, Cui Liang-Wei $2,3,4,5^{*}$, Xiao Wen ${ }^{1,2,3,4 *}$

${ }^{1}$ Institute of Eastern-Himalaya Biodiversity Research, Dali University, Dali, Yunnan 671003,

${ }^{3}$ The provincial innovation team of biodiversity conservation and utility of the three parallel rivers region from Dali University, Dali, Yunnan 671003, China;

${ }^{4}$ The key laboratory of Yunnan education department on Er'hai catchment conservation and sustainable development, Dali University, Dali, Yunnan 671003, China;

${ }^{5}$ Faculty of Biodiversity Conservation and Utilization, Southwest Forestry University, Kunming, Yunnan 650224, China;

${ }^{6}$ School of Archaeology \& Anthropology, Australian National University, Canberra, ACT 0200, Australia.

\# Equality contribution to this article

* Correspondence to: Xiao Wen xiaow@eastern-himalaya.cn;

Cui liangwei cuilw@,eastern-himalaya.cn.

\section{Abstract}

Light pollution has become one of the top issues in environmental pollution, especially concerning how secondary light pollution, such as from traffic reflective materials, influences animal distribution and behavior. In this study, 15 camera traps were set up at sites with or without reflective warning markers (RWM) in coniferous forests on Cangshan Mountain located in Dali Prefecture, China. The results showed that the number of independent photographs and species at sites without RWMs were significantly higher than those at sites with RWMs.

Significant differences were found between daytime and nighttime composition of bird species and non-flying mammals between two sites. This study found that RWMs had negative effects on wildlife, with the avoidance response of birds to RWMs being more obvious than that of 
32 animals at daytime. It is recommended that the use of reflective materials be carefully

33 considered, especially in protected areas.

34

35 Keywords: reflective materials; secondary light pollution; camera trap; daytime; nighttime.

\section{Introduction}

Artificial structures are having a growing influence on biodiversity (Pechmann et al., 1991 ; Soga et al., 2014). The development of cities and roads is considered as one of the most important factors influencing the survival of wildlife, often with complex effects (Sauvajot et al., 1998; Seto et al., 2012; Bennie et al., 2015) such as altering wildlife habitats, increasing habitat fragmentation, directly damaging wildlife, and indirectly affecting wildlife by changing ambient sounds, light and odors s(McLellan and Shackleton, 1988; Trombulak and Frissell, 2000; Forman and Deblinger, 2000; Coffin, 2007; Bolger et al., 2008; Summers et al., 2011; Arevalo et al., 2011). Light pollution from road lighting systems is considered as one of the most serious environmental interferences (Hölker et al., 2010), with 35\% to 50\% of light pollution being generated from the traffic lighting systems. This has become an increasingly important environmental problem (Stoilova and Stoilov, 1998; Lyytimäki, 2013). Reflective warning markers (RWMs) have been widely used on highways, smaller roads, in urban areas (Wolshon et al., 2002), and other areas that are being developed due to expanding urbanization and road construction. In addition, various types of RWMs are frequently used in agriculture, horticulture (Layne et al., 2002), architectural engineering (Li et al., 2008), and even in protected areas (Reinius and Fredman, 2007; Wu et al., 2007).

How RWMs influences wildlife has been rarely considered. The materials used in RWMs are not self-luminous and directs people with conspicuous colors in the daytime and by reflection at night. Conspicuous colors, such as red, are commonly considered to be aposematic, or natural warning signals, and are used by insects and birds to signal their undesirability to potential predators (Stevens, 2007, Myczko et al., 2015, Iniesta et al., 2017). Although the intensity of reflected light at nighttime is low intensity but noticeable, it is still regarded as a special source of light pollution (defined as secondary light pollution). Similar reflector materials are sometimes used to alter the behavior off animals and direct their movement away from roads to 
62 reduce wildlife-vehicle collisions (Anke et al., 2018). However, there is still a large gap in the

63 research of physiological and ecological effects of night illumination on animals (Gaston and

64 Bennie, 2014).

65 A goal of this study was to understand how RWMs influence wildlife. By comparing animal

66 species with independent photographs shot by the cameras grouped at stations with and without

67 RWMs, this study assessed how nighttime reflection and a daytime warning color affected wild

68 animal species. The results will provide guidance on the future use of RWMs.

69

70

\section{Study area and camera trapping}

72 Cangshan Mountain, located in Dali Prefecture of Yunnan Province, China (Fig. 1a), is in the

73 Cangshan Mountain and Erhai Lake Nature Reserve. Previous surveys have shown Cangshan

74 Mountain is rich in native flora and fauna (Shen, 1998; Zhao et al., 2017). The study site is

75

76

77

78

79

80

81

82

83

84

85

86

87

88

89

90

91

92

located between Mocan and Heilong streams $\left(25^{\circ} 36^{\prime}-25^{\circ} 40^{\prime} \quad \mathrm{N}, 100^{\circ} 06^{\prime}-100^{\circ} 11^{\prime}\right.$ E, altitude range $2,550-2,800 \mathrm{~m}$, Fig. 1a). Vegetation at the site has a ground cover of $40 \%-80 \%$ and is dominated by 15-20 m tall Armand pine (Pinus armandii). Human activities are strictly controlled in this nature reserve and almost no artificial light enters the study area.

To avoid impacts caused by environmental heterogeneity, five sub-regions were selected on a single slope of a stream divide. From April 9, 2017 to July 23, 2017, 30 camera traps were set up in study stations. Within each sub-region, three stations included RWMs (RWM group), and another three stations were without RWMs (control group) (Fig. 1a). The distances between the nearest two camera traps were 100-200 m. The RWMs were installed $4 \mathrm{~m}$ in front of the camera traps and $0.3 \mathrm{~m}$ aboveground (Fig. 1c). The size of the RWMs were $20 \mathrm{~cm} \times 5 \mathrm{~cm}$ and were designed with $10 \mathrm{~cm} \times 5 \mathrm{~cm}$ red colored strips and $10 \mathrm{~cm} \times 5 \mathrm{~cm}$ white colored strips. Both strips reflect light but are not self-luminous (Fig. 1b).

Ltl Acorn ${ }^{\circledR}$ 6310MC cameras were used and set at medium sensitivity for motion, with two photos and a $10 \mathrm{~s}$ video captured in rapid succession upon each trigger. Camera installation and basic photographing methods followed specifications proposed by Xiao et al. (2014). All cameras made by Zhuhai Ltl Acorn Electronics Co., LTD in Zhuhai city of Guangdong province, China. 


\section{Data Processing and statistical analysis}

94 When the camera traps were collected, all memory cards and data were processed using software

95 M-photov1.0 (a software for manually sorting camera trap photographs that was developed

96 independently by the Institute of Eastern-Himalaya Biodiversity Research, Dali university,

97 http://www.eastern-himalaya.com.cn/contents/3/990.html). Animals on the photos were

98 identified to the species level with the time and date being noted. The identification of mammal

99 species was accomplished using Smith et al. (2010) and bird species were identified using

100 MacKinnon et al. (2000). Nocturnal mammals such as rodents and bats were excluded from the 101 analysis because they could not be accurately identified on the photographs captured at night.

102 O'Brien et al. (2003) used several independent photographs to estimate species abundance and

103 activities. We used the same method to uniquely define each photograph in a series consecutive 104 photos taken of the same or different species, or of the same individuals taken during $30 \mathrm{~min}$.

105 Nighttime was defined as lasting from 19:30 to 6:30, and daytime lasted from 6:30 to 19:30.

106 To assess if RWMs significantly changed the diversity and abundance of species, we used a 107 general linear mixed model, with the number of species and independent photographs captured 108 separately on each camera as the dependent variables (Bolker et al., 2009). In both RWMs 109 groups, we considered the sub-regions as random-effects, and the presence or absence of RWM 110 as the fix-effects. We conducted a covariance analysis to test if the slope of the independent 111 acumination line between the two groups was significantly different.

112 To estimate the species composition between the groups, we used the Jaccard index (Jaccard, 113 2010), which is a community similarity index calculated as $q=c /(a+b-c)$, where $q$ is the 114 Jaccard index, $a$ and $b$ are the number of species in each group, and $\mathrm{c}$ is the number of common 115 species in both groups. Indices between: $0 \leqq \mathrm{q} \leqq 0.25$ were considered extremely dissimilar, $1160.25<\mathrm{q} \leqq 0.50$ were moderately dissimilar, $0.50<\mathrm{q} \leqq 0.75$ were moderately similar, and 0.75

$117<\mathrm{q} \leqq 1$ were extremely similar. All analyses were completed with Software R (R Core Team, 118 2018).

\section{Results}

121 In this study, the 30 cameras effectively worked for 76 days and recorded 25 wild animal species 122 belonging to 14 families, 11 of which were mammal species and 14 were bird species, 
123 (Appendix 1). More than 75\% of the species were recorded in the first 30 days in the RWM 124 group and in the first 31 days in the control group, indicating that the sampling effort was 125 adequate (Fig. 2a).

126

\section{Number of species and independent photos}

128 The camera traps captured 13 (RWM group) and 21 (control group) species. The linear mixed 129 model analysis showed that the cameras with RWMs recorded significantly higher species 130 number than those without $(2.60 \pm 1.99$ vs. $4.93 \pm 2.99, t=-2.70, \mathrm{p}=0.012$, Appendix 2). 131 Cameras traps with RWMs captured 146 independent photographs, whereas the control group 132 had 284 photographs (Fig. 2b). Although not significantly different, cameras with RWMs 133 captured fewer independent photographs than did cameras without RWMs (10.00 \pm 13.52 vs. $13420.13 \pm 21.3, \mathrm{t}=1.66, \mathrm{p}=0.130$, Appendix 2). Stations with RWMs had a lower number of 135 independent photos than did the control group in all five sub-sampling regions, indicating these 136 regions had a lower animal density. (Fig. 3). The slopes of the number of independent 137 photographs by dates for the two groups were significantly different $(\mathrm{df}=152, \mathrm{t}=20.60, \mathrm{p}<$ $1380.001)$.

139

140 Composition of community species

141 Among the 25 species of animals captured by camera traps, seven of the mammalian species and 142 one avian species was recorded in both treatments (Fig. 4). The Jaccard index of species for both 143 treatments was $32 \%$, which was classified as moderately dissimilar. However, the bird species 144 composition was extremely dissimilar between two groups (Jaccard $=7.6 \%$ ), and the mammal 145 species composition was moderately similar ( Jaccard $=58.3 \%)$.

146 More species and independent photographs were captured in the daytime than in the nighttime

147 for both groups (Fig. 5). Eleven bird species and four mammal species were only captured in the 148 daytime, and one bird species and five mammal species were only captured at night. Two 149 mammal species, the long-tailed goral (Naemorhedus caudatus) and leopard cats (Prionailurus 150 bengalensis), were captured during daytime and nighttime in both groups (Fig. 6).

151 Among the species captured in the daytime, long-tailed thrushes (Zoothera dixoni) and 152 moustached laughingthrushes (Garrulx cineraceus) only appeared in areas with RWMs. Ten 153 other bird species only appeared in the areas without RWMs. One bird species, the Lady 
154 Amherst's pheasant (Chrvsolophus amherstiae), and four mammal species were captured in both 155 groups (Fig. 6).

156 Tawny owls (Strix aluco), Yunnan hares (Lepus comus), and Malayan porcupines (Hystrix

157 brachyura) were only captured at night in the stations with RWMs, whereas masked palm civets

158 (Paguma larvata) and red muntjacs (Muntiacus muntjak) only appeared in areas without RWMs. 159

\section{Discussion}

161 The effects of light pollution on wildlife have been widely documented (Cabrera-Cruz, 2018;

162 McLaren, 2018). Jones and Francis (2003) dramatically reduced the mortality of migratory birds 163 by decreasing the intensity and power of light beams. Adrien et al. (2018) claimed that artificial 164 lights, primarily from highways and associated traffic, were continuously increasing in protected 165 areas and biodiversity hotspots around the world. In our study, artificial lights were rare and 166 nearly all reflected light originated from the moon and sun. Our study areas could be different 167 from other areas that experience strong artificial light. However, the present study strongly 168 suggests that light pollution during daytime and RWMs secondary light pollution during 169 nighttime may influence wildlife distribution.

170

171 Effects of RWMs on wildlife during nighttime

172 Although the number of species during nighttime differed slightly between the camera groups 173 with and groups without RWMs, the number of independent photographs in the stations with 174 RWMs was nearly 50\% lower than the control group. The differences might be related to the 175 different density or activities pattern of the species recorded in both groups. Of the eight species 176 captured at night, tawny owls, Yunnan hares, and Malayan porcupines were only found in the 177 areas with RWMs. Tawny owls are a nocturnal predatory species that preys mainly on small 178 rodents. The short-eared owl (Asio flammeus) is another owl that has been found to have better 179 predation efficiency at night. Consequently its prey, deer mice (Peromyscus maniculatus), have 180 decreased their foraging behavior and other activities to avoid detection in highlighted 181 environments (Navara and Nelson, 2007). Therefore, the materials might be attractive to the owls 182 because they might use light reflected by RWMs during hunting.

183 The three species that only appeared in the areas without RWMs were primarily prey species 184 within an ecosystem. Their predation avoidance abilities may keep them from appearing in 
185 places with RWMs that may assist predators. Leopard cats and wild boars appeared in both 186 groups, perhaps because they are highly adaptable and live around human residential areas. The 187 leopard cats hunt near villages and wild boars search for food in farmlands (Rajaratnam et al., 188 2007; Schley and Roper, 2003).

\section{Effects of RWMs on wildlife in the daytime}

191 During the daytime, there were considerable differences in the number of species and 192 independent photographs captured between the two groups. The stations with RWMs had nearly $19330 \%$ fewer species and 50\% fewer independent photographs. The daytime differences in species 194 composition were probably caused by the different community composition of birds. Seven 195 babblers captured, of which six were in the control group and only one was found the in RWM 196 group. White-bellied pheasants were the only species that showed no avoidance response in the 197 RWM groups during daytime. Red colored RWMs can increase visual stimulation in a manner 198 similar to the alert color of insects (Stevens, 2007; Iniesta, 2017). A bird-repelling device has 199 invented and functions effectively by using a red material that reflects light in an intermittent pattern (Doty et al., 2003).

201

202 Conclusions

203 Results of this study suggest that RWMs, as crucial road components, can significantly affect the 204 distribution of wildlife. Thus, it is necessary to consider the environmental effects of RWMs in 205 assessing road construction. At present, some countries and regions have introduced standards 206 and policies on night lighting and regulations to control light pollution (Cha et al., 2014; Raap et 207 al., 2015; Ryu and Lee, 2015; Lyytimäki, 2013); Presently there are no policies on the use of the 208 RWMs.

209 We propose that specifications be added to regulations on the use of reflective warning signs for 210 ecological important sites, such as protected areas and national parks. The use of reflective 211 warning signs should be carefully considered, including the plastic and glass materials that have 212 similar reflection and warning effects. The use of RWMs should be minimized in important 213 biological corridors that cross highways to reduce traffic interference with wildlife migration.

214 Concurrently, installing RWMs in traffic corridors may prevent wild animals from moving onto 215 highways and consequently reduce the rate of traffic accidents involving animals (Reed et al., 
216 1975). The avoidance response of wildlife to RWMs can also be used for repelling bird in 217 orchards, farmlands, and feed mills. Color signals can alert birds to danger and lower the 218 frequency of accidents with non-reflective or non-glare clear glass (LeMessurier, 1986; Doty et 219 al., 2003Doty, 2003; Klem, 2009). Wind turbine blades and power-supply cables can be made

220

221

222

223

224

225

226

227

228

229

230

231

232

233

234

235

236

237

238

239

240

241

242

243

244

245

246

247

248

249

250

251

252

253

254

255

with red and white warning colors that can protect birds from flying into fan blades (Wei et al.,

2011). In sum, wildlife responses to RWMs can be used for improving wildlife management;

however, more studies are needed to better understand how RWMs influence wildlife.

\section{Acknowledgements}

Thanks Mr. Zhu xiaoming for his help in the article writing. This study was supported by the National Natural Science Foundation of China (\#31560599, \#31560118, \#31860164, and \#31860168), the Program for Backup Talents of Young Academic and Technical Leaders in Yunnan Province (2015HB047), and the Yunnan provincial program of 10,000 intellects leading intellects for industrial technologies. We also wish to thank the China Green Foundation for their support.

\section{References}

Adrien G, Laurent G, Martin J, Marc R. 2018. Worldwide increase in artificial light at night around protected areas and within biodiversity hotspots. Biological Conservation, 223: 97-103 doi.org/10.1016/j.biocon.2018.04.018.

Anke B, Peter A, Torsten V. 2018. Wildlife warning reflectors' potential to mitigate wildlife-vehicle collisions-a review on the evaluation methods. Frontiers in Ecology and Evolution, 6, 37. doi.org/10.3389/fevo.2018.00037.

Arevalo JE, Newhard K. 2011. Traffic noise affects forest bird species in a protected tropical forest. International Journal of Tropical Biology, 59(2): 969-980 doi. org/10.15517/RBT.V0I0.3152.

Bennie J, Duffy J, Davies T, Correa-Cano M, Gaston K. 2015. Global trends in exposure to light pollution in natural terrestrial ecosystems. Remote Sensing, 7(3): 2715-2730 doi.org/10.3390/rs 70302715.

Bolger DT, Newmark WD, Morrison TA, Doak DF. 2008. The need for integrative approaches to understand and conserve migratory ungulates. Ecology letters, 11(1), 63-77 doi.org/10.1111/j.14610248.2007.01109.x.

Bolker BM, Brooks ME, Clark CJ, Geange SW. Poulsen JR. Stevens MH. White JS. 2009. Generalized linear mixed models: a practical guide for ecology and evolution. Trends in Ecology and Evolution, 24(3): 127-135 doi.org/10.1016/j.tree.2008.10.008.

Cabrera-Cruz SA, Smolinsky JA, Buler JJ. 2018. Light pollution is greatest within migration passage areas for nocturnally-migrating birds around the world. Scientific reports, 8(1), 3261 doi.org/10.1038/s41598-01821577-6

Cha JS, Lee JW, Lee WS, Jung JW, Lee K M, Han JS, Gu JH. 2014. Policy and status of light pollution management in Korea. Lighting Research and Technology, 46(1): 78-88 doi.org/10.1177/1477153513508971. 
256

257

258

259

260

261

262

263

264

265

266

267

268

269

270

271

272

273

274

275

276

277

278

279

280

281

282

283

284

285

286

287

288

289

290

291

292

293

294

295

296

297

Coffin AW. 2007. From road kill to road ecology: a review of the ecological effects of roads. Journal of transport Geography, 15(5): 396-406 doi.org/10.1016/j.jtrangeo.2006.11.006.

Doty III AF, Turkewitz RM, Byers EG. U.S. Patent No. 6,557,482. Washington, DC: U.S. Patent and Trademark Office, 2003.

Forman RT, Deblinger RD. 2000. The ecological road-effect zone of a Massachusetts (USA) suburban highway. Conservation biology, 14(1): 36-46 doi.org/10.1046/j.1523-1739.2000.99088.x.

Hölker F, Wolter C, Perkin EK, Tockner K. 2010. Light pollution as a biodiversity threat. Trends in Ecology and Evolution, 25: 681-682 doi.org/10.1016/j.tree.2010.09.007.

Iniesta LF, Ratton P, Guerra TJ. 2017. Avian predators avoid attacking artificial aposematic millipedes in Brazilian Atlantic Forest. Journal of Tropical Ecology, 33(1): 89-93 doi.org/10.1017/S0266467416000523.

Jaccard P. 2010. The distribution of the flora in the alpine zone. New Phytologist, 11: 37-50 doi.org/10.1111/j.1469-8137.1912.tb05611.x.

Jones J, Francis CM. 2003. The effects of light characteristics on avian mortality at lighthouses. Journal of Avian Biology, 34(4): 328-333 doi.org/10.1111/j.0908-8857.2003.03183.x.

Kevin J, Gaston, Jonathan Bennie. 2014. Demographic effects of artificial nighttime lighting on animal populations. NRC Research Press, 22(4): 323-330 doi.org/10.1139/er-2014-0005.

Klem JD. 2009. Preventing bird-window collisions. The Wilson Journal of Ornithology, 121(2): 314-322 doi.org/10.1676/08-118.1.

Layne D R, Jiang Z, Rushing JW. 2002. The Influence of Reflective Film and ReTain on Red Skin Coloration and Maturity of Gala Apples. Hort Technology, 12(4): 640-645 doi.org/10.21273/HORTTECH.12.4.640.

LeMessurier DH. 1986 . U.S. Patent No. 4,597,357. Washington, DC: U.S. Patent and Trademark Office.

Li S, Xue Y, Zhang Q, Li S, Li L, Sun K, LI X. 2008. Key technology study on comprehensive prediction and early-warning of geological hazards during tunnel construction in high-risk karsts areas. Chinese Journal of Rock Mechanics and Engineering, 7: 003. http://en.cnki.com.cn/Article_en/CJFDTOTAL-YSLX200807003.htm

Lyytimäki J. 2013. Nature's nocturnal services: light pollution as a non-recognised challenge for ecosystem services research and management. Ecosystem Services, 3:e44-e48 doi.org/10.1016/j.ecoser.2012.12.001.

MacKinnon JR, MacKinnon J, Phillipps K, He FQ. 2000. A field guide to the birds of China. Oxford University Press.

McLaren JD, Buler JJ, Schreckengost T, Smolinsky JA, Boone M, van Loon EE, Dawson DK, Walters EL. 2018. Artificial light at night confounds broad-scale habitat use by migrating birds. Ecology letters. 21(3): 356-364 doi.org/10.1111/ele.12902.

McLellan BN, Shackleton DM. 1988. Grizzly bears and resource-extraction industries: effects of roads on behavior, habitat use and demography. Journal of Applied Ecology, 451-460 doi: $10.2307 / 2403836$.

Myczko L, Skórka P, Dylewski Ł, Sparks TH, Tryjanowski P. 2015, Color mimicry of empty seeds influences the probability of predation by birds. Ecosphere, 6(10): 1-7 doi.org/10.1890/ES1500055.1. 
298

299

300

301

302

303

304

305

306

307

308

309

310

311

312

313

314

315

316

317

318

319

320

321

322

323

324

325

326

327

328

329

330

331

332

333

334

335

336

337

338

339

340

Navara KJ, Nelson RJ. 2007. The dark side of light at night: physiological, epidemiological, and ecological consequences. Journal of Pineal Research, 43(3):215-224 doi.org/10.1111/j.1600079X.2007.00473.x.

O'Brien TG, Kinnaird MF, Wibisono HT. 2003. Crouching tigers, hidden prey: Sumatran tiger and prey populations in a tropical forest landscape. Animal Conservation, 6: 131-139 doi.org/10.1017/S1367943003003172.Pechmann JH, Scott DE, Semlitsch RD, Caldwell JP, Vitt LJ, Gibbons JW. 1991. Declining amphibian populations: the problem of separating human impacts from natural fluctuations. Science, 253(5022): 892-895 doi: 10.1126/science.253.5022.892.

R Core Team. 2018. R: A language and environment for statistical computing. R Foundation for Statistical Computing, Vienna, Austria. URL https://www.R-project.org/.

Raap T, Pinxten R, Eens M. 2015. Light pollution disrupts sleep in free-living animals. Scientific reports, 5, 13557 doi.org/10.1038/srep13557.

Rajaratnam R, Sunquist M, Rajaratnam L, Ambu L. 2007. Diet and habitat selection of the leopard cat (Prionailurus bengalensis borneoensis) in an agricultural landscape in Sabah, Malaysian Borneo. Journal of Tropical Ecology, 23(2): 209-217 doi.org/10.1017/S0266467406003841.

Reed, DF., Woodard, TN., Pojar, TM. 1975. Behavioral response of mule deer to a highway underpass. The Journal of Wildlife Management, 361-367 DOI: 10.2307/3799915.

Reinius SW, Fredman P. 2007. Protected areas as attractions. Annals of tourism research, 34(4): 839854 doi.org/10.1016/j.annals.2007.03.011.

Ryu JS, Lee JS. 2015. A Study on Status and Analysis of Local Governments Light Pollution Control Ordinance. Journal of the Korean Institute of Illuminating and Electrical Installation Engineers, 29(10): 7-16 doi.org/10.5207/JIEIE.2015.29.10.007.

Sauvajot RM, Buechner M, Kamradt DA, Schonewald CM. 1998. Patterns of human disturbance and response by small mammals and birds in chaparral near urban development. Urban Ecosystems, 2(4): 279-297 doi.org/10.1023/A:1009588723665.

Schley L, Roper TJ. 2003. Diet of wild boar Sus scrofa in Western Europe, with particular reference to consumption of agricultural crops. Mammal review, 33(1): 43-56 doi.org/10.1046/j.13652907.2003.00010.x.

Seto KC, Güneralp B, Hutyra LR. 2012. Global forecasts of urban expansion to 2030 and direct impacts on biodiversity and carbon pools. Proceedings of the National Academy of Sciences, 109(40): 16083-16088 doi.org/10.1073/pnas.1211658109.

Shen B. 1998. Studies on the resource exploitation and biodiversity conservation in Dali Cangshan Erhai Nature Reserve. Chinese biodiversity, 2.

Smith AT, Xie Y, Hoffmann RS, Lunde D, MacKinnon J, Wilson DE, Wozencraft WC (Eds.). 2010. A guide to the mammals of China. Princeton University Press.

Soga M, Yamaura Y, Koike S, Gaston KJ. 2014. Land sharing vs. land sparing: does the compact city reconcile urban development and biodiversity conservation?. Journal of Applied Ecology, 51(5):1378-1386 doi.org/10.1111/1365-2664.12280.

Stevens M. 2007. Predator perception and the interrelation between different forms of protective coloration. Proceedings of the Royal Society B: Biological Sciences, 274(1617): 1457-1464 doi.org/10.1098/rspb.2007.0220.

Stoilova K, Stoilov T. 1998. Traffic noise and traffic light control. Transportation Research Part D: Transport and Environment, 3(6):399-417 doi.org/10.1016/S1361-9209(98)00017-0. 
341 Summers PD, Cunnington GM, Fahrig L. 2011. Are the negative effects of roads on breeding birds

342

343

344

345

346

347

348

349

350

351

352

353

354

355

356

357

358

359

360

361

caused by traffic noise? Journal of Applied Ecology, 48(6):1527-1534 doi.org/10.1111/j.13652664.2011.02041.x.

Trombulak SC. Frissell CA. 2000. Review of ecological effects of roads on terrestrial and aquatic communities. Conservation biology, 14(1): 18-30 doi.org/10.1046/j.1523-1739.2000.99084.x.

Wei KJ, Jiang HP, Wang W, Zhou XH, Zou FS. 2011. Influence of Xuwen Wind Power Field on Birds. Environmental science and management, 36(7):153-157. (in Chinese with English abstract)

Wolshon B, Degeyter R, Swargam J. 2002. Analysis and predictive modeling of road sign retroreflectivity performance. In 16th Biennial Symposium on Visibility and SimulationTransportation Research Board; University of Iowa, Center for Computer Aided Design, Operator Performance Laboratory.

Wu XB, Zhang LM, Zou W. 2007. Construction of tourism interpretive panels system of nature reserve - an example of shennongjia national nature reserve. Journal of Guilin Institute of Tourism, 5. (in Chinese with English abstract)

Xiao ZS, Li XH, Wang XZ, Zhou QH, Quan RC, Shen XL, Li S. 2014. Developing camera-trapping protocols for wildlife monitoring in Chinese forests. Biodiversity Science, 22(6), 704-713. (in Chinese with English abstract)

Zhao JS, Zhang JW, Bai MY, Zhao Q, Xu HL, Xiao W. 2017. The dynamic temporal and spatial distribution of wildanimals in Cangshan Mountains, Dali. Journal of yunnan university (natural science edition), 39(4):691-700. (in Chinese with English abstract)

Peer] reviewing PDF | (2019:03:35930:2:1:NEW 1 Aug 2019) 


\section{Figure 1}

Study area and the camera trap with a reflective warning marker

(a)the location and stretch map of the study site.(b) Reflective warning marker (RWM). (c). a camera trap and the RWM installation, (d)a leopard cat captured moving in front of the RWM by a camera trap.
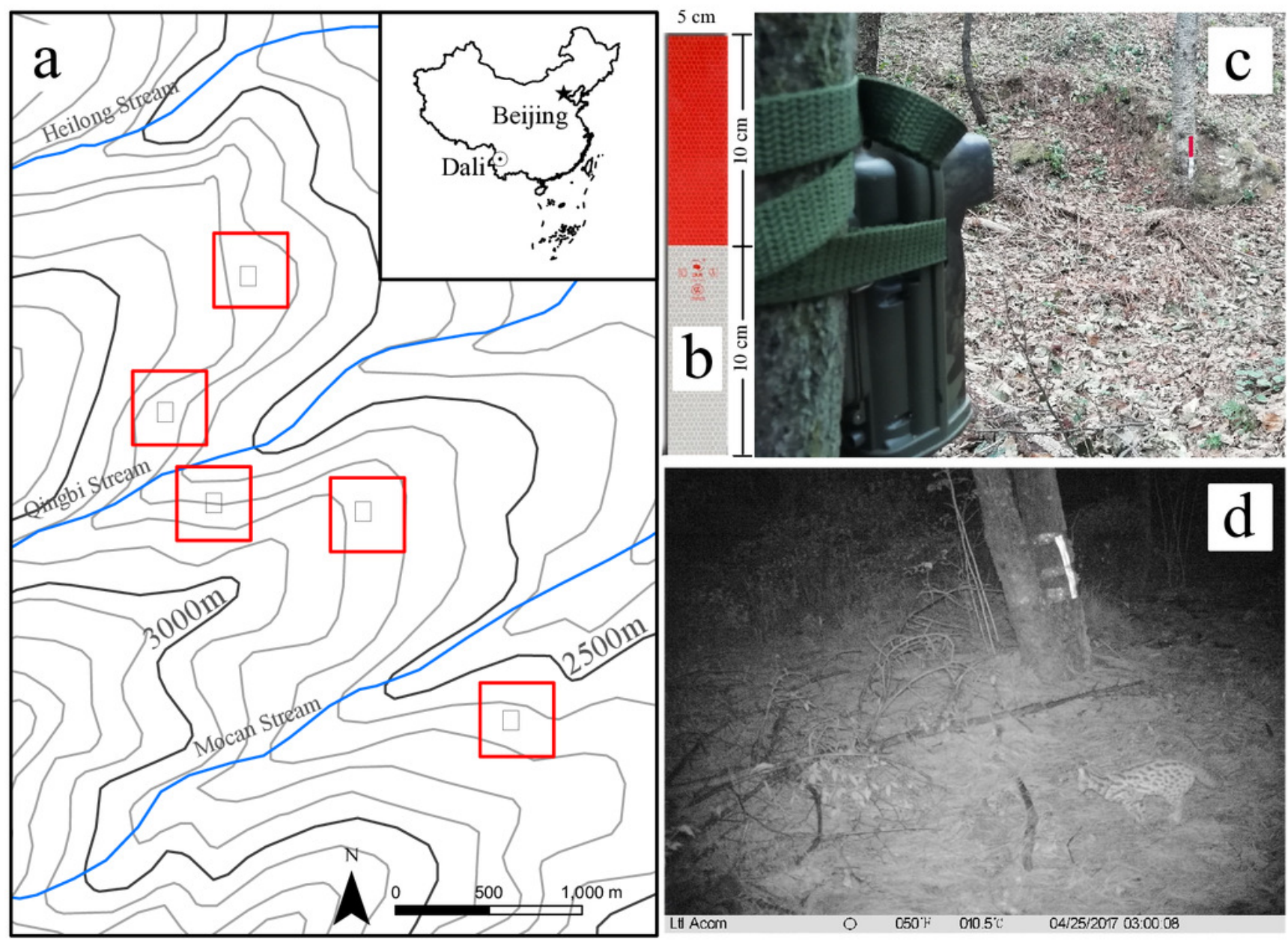
Figure 2

Cumulative curves of species number and independent photographs

a. The cumulative curves of species number in RWM group (brown line) and control group (green line); the dotted line show when $75 \%$ of species were recorded the corresponding group. b. The cumulative curves of independent photographs in RWM group (brown line) and control group (green line);
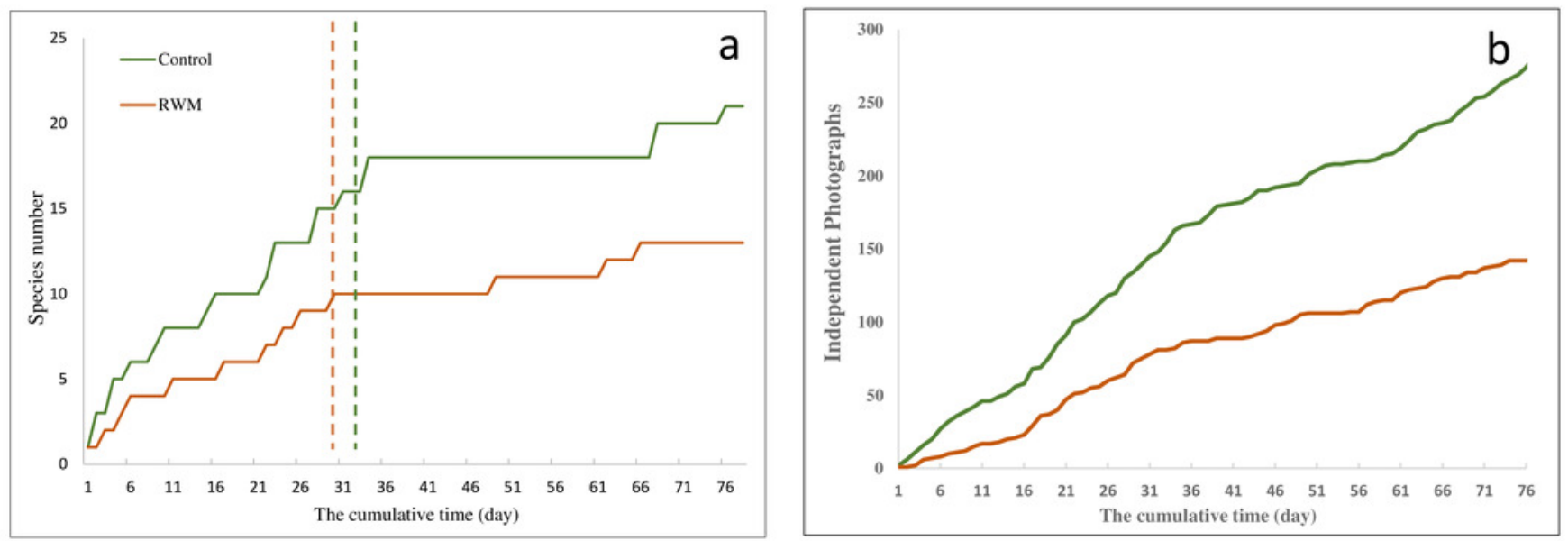
Figure 3

Independent photographs of sub-regions

Independent photographs number of RWM group (brown, mean \pm SD) and control group (green) in the five sub-regions (I, II, III, IV, V)

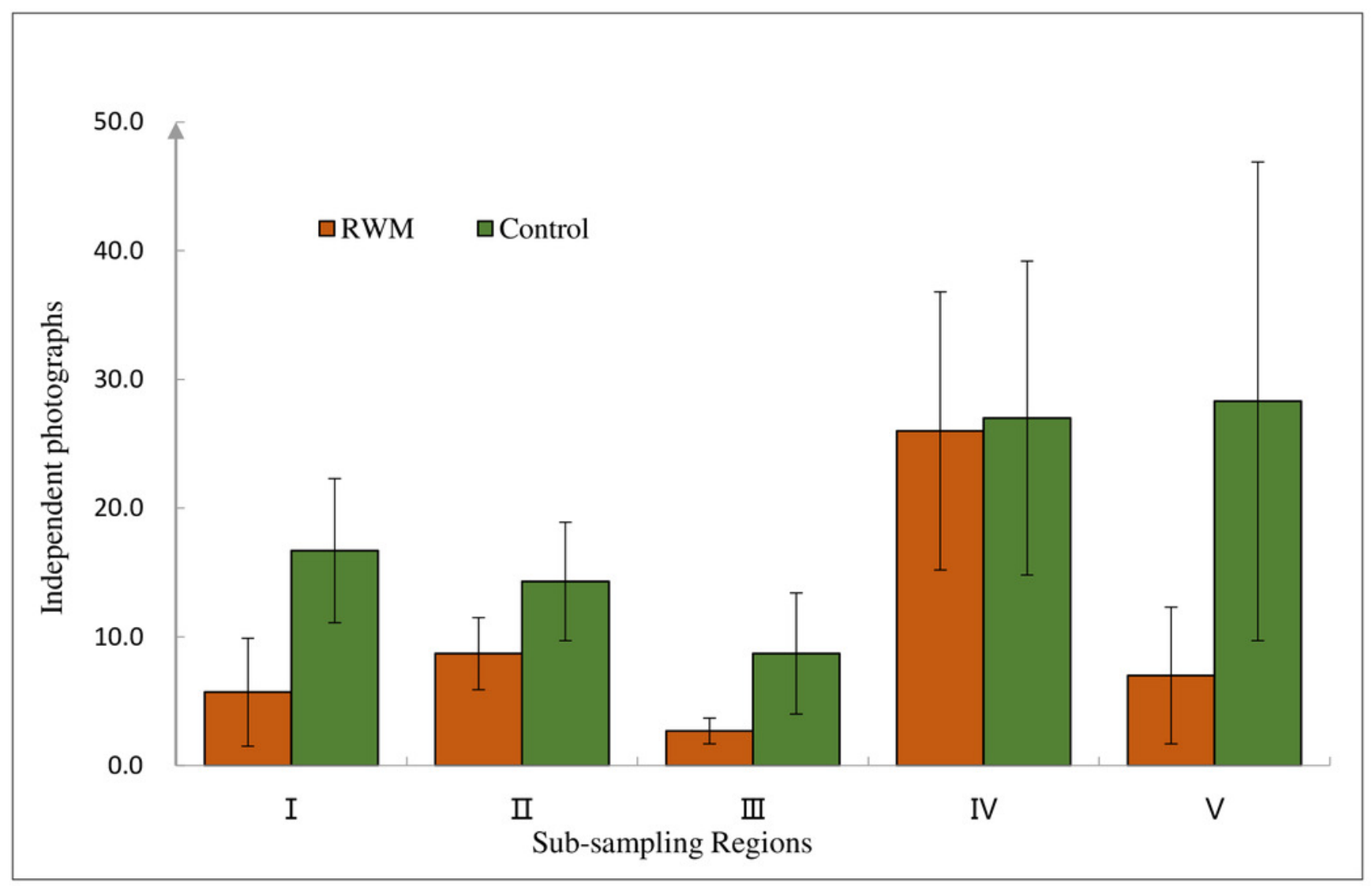


Figure 4

Species number captured in the sub-regions

The species numbers captured in both group (purple), only in the RWM group (blue) and control group (blue) in the five regions (I, II, III, IV, V) and all regions (T)

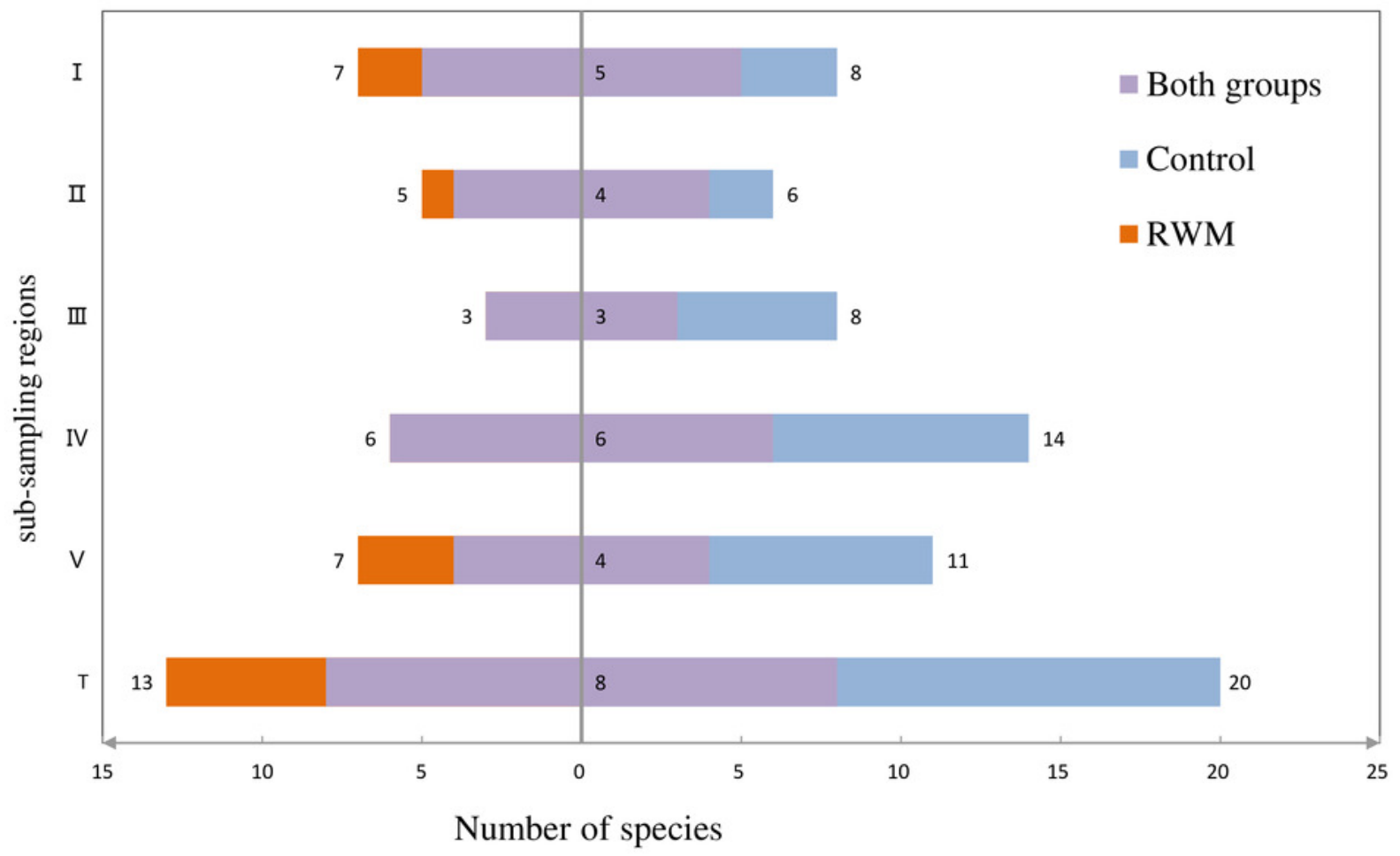


Figure 5

Species number and Independent photographs number captured in the day and the night

Species number (column) and Independent photographs number (dot) captured in RWM (blue) and Control (orange) groups during the day and the night

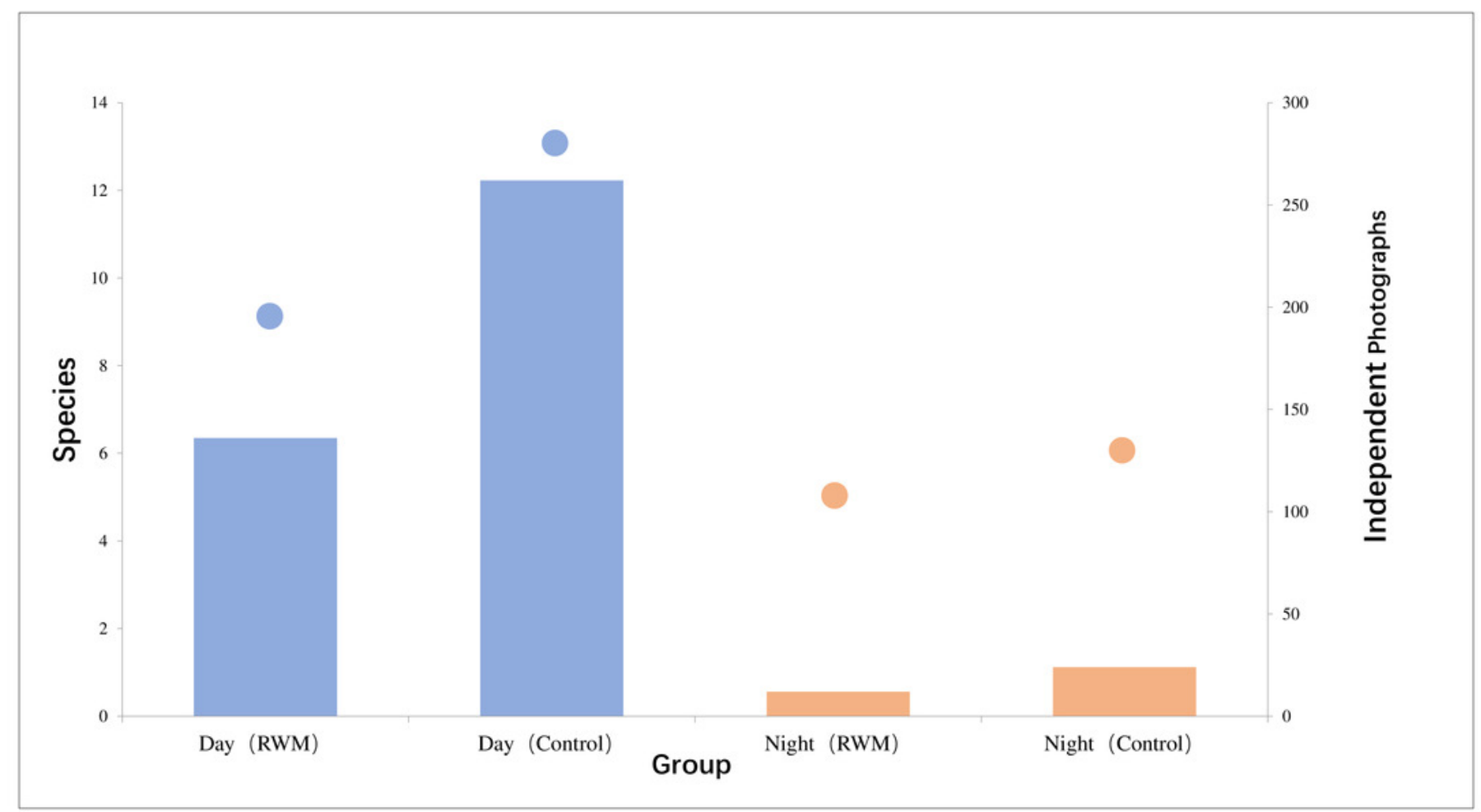


Figure 6

The percentage of independent photographs of species in the day and night

The percentage of independent photographs of species recorded in RWM (brown) and Control(blue) groups in the daytime (up) and nigttime(down)

* bird

\# mammal

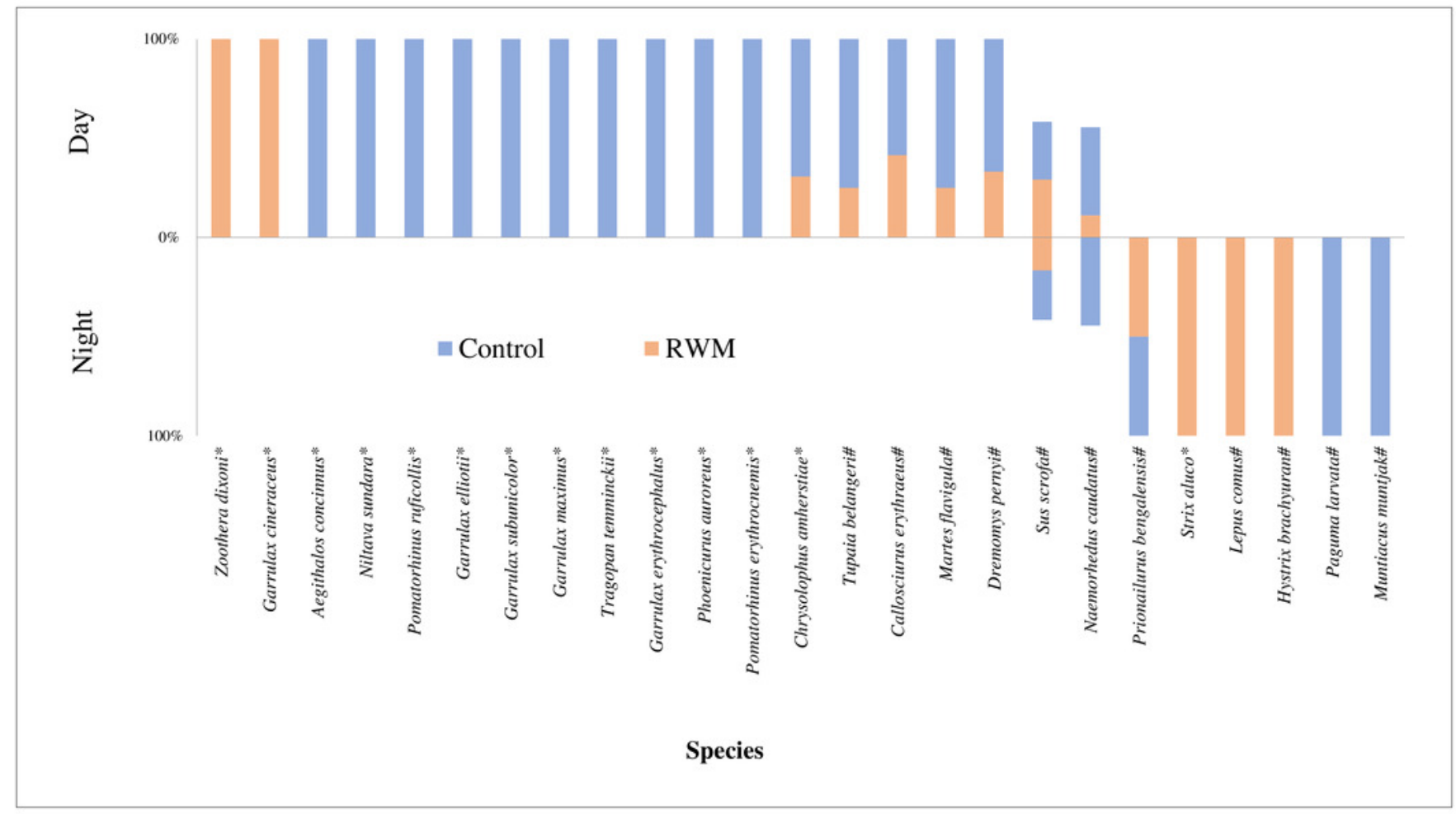

